\title{
How to read 'Emotional Cartographies': Rethinking (Carto)graphic Representation and Semantics
}

\author{
Nevena Marković ${ }^{\mathrm{a}, ~ *}$ \\ ${ }^{a}$ The Institute of Heritage Sciences - Incipit (The Spanish National Research Council - CSIC), The University of the Basque \\ Country,nevena.markovic@incipit.csic.es \\ * Corresponding author
}

Keywords: Emotional Geographies, Emotional Cartographies, Conceptual Semantics, Spatial Humanities, Narrative Landscape

\begin{abstract}
:
The emotions, in its broadest sense, have been the subject of anthropological, sociological, and cultural studies among geographers. The "mapping impulse" has been also an essential element and a major force in many disciplines and fields.

Historically, the mapping has imposed not only physical but also imagined boundaries, imposing "the powerknowledge" relations on the landscape and its communities. At the same time, looking at the history of cartography, the visual vocabulary of conventional maps has been used to interpret various facets of the human psyche, for instance in the case of the late Renaissance "sentimental cartography".

The concept of 'Emotional Geographies' has been adopted by geographers as 'a concern with the spatiality and temporality of emotions' (Davidson J, 2007). Hence, emotions have been acknowledged not as individualized, but as intersubjective - social and cultural.

Although the geospatial technologies have acquired more humanized characteristics since the mid 1990's (Pickles, 1995), such as mapping feelings (Pocock, D. 1984) and emotional responses to space (Gartner, 2012), the cartography has been facing challenges regarding of data collection and representation of emotions (Griffin \& McQuoid, 2012). Therefore, little cartographic efforts have been made in that direction due to the challenges in data collection and representation of emotions. (Griffin \& McQuoid, 2012).

As such, "turned" not only by the affective topographic or non-spatial elements, but also the critical theory, "Emotional Mapping", as an additional concept in cartography, goes beyond the georeferenced emotional states in a certain geographic area. This reflexive methodology combines technology, science and art, theory and practice, and, as Nold argues, enables "Reflection-In-Action", and new social relations. But, the way in which it creates a tangible vision of places as a dense multiplicity of personal sensations, which we are not normally aware of, is its most significant aspect (Nold, 2009). Further to new psychology-based approaches to affect and emotion, and how maps make us feel (Griffin \& McQuoid, 2012), alternative approaches from cartography, social theory and art, demonstrate how maps are meaningful. In such scholarship environment, the co-creation of "Emotional Mapping" has a potential by drawing on "Emotional Cartography" techniques, and exploring the ways in which emotional responses might be sensed, captured, represented, analysed, and used in various cross-disciplinary projects.
\end{abstract}

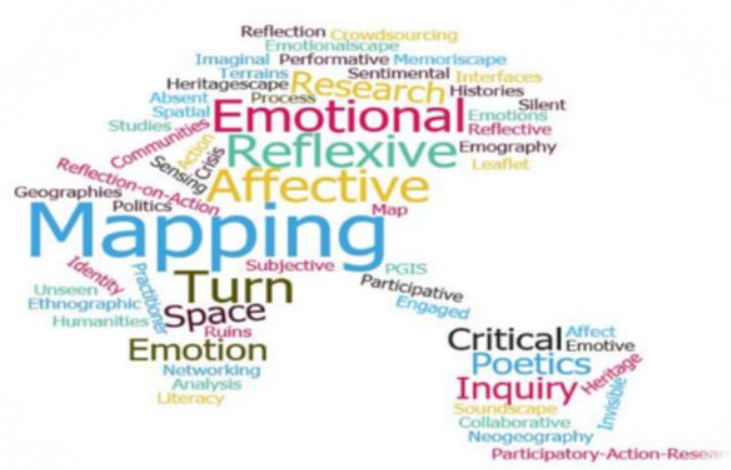

Figure 1. Concept Map: The State of Art of "Emotional Cartographies". Credits: Author. 
With the objective to establish the State of the Art and the State of the Practice of this emerging field, this research rethinks "Emotional Cartographies' in the era of "Turns": How "Emotional Cartography" has been linking Spatial, Affective, Participatory and Digital "Turns"? Have these "Turn" provided new research models for Critical Heritage Studies, or Humanities, in general? What are contribution and limitations of "Emotional Mapping" as a tool?

Being particularly interested in "invisible", "unseen", or "absent" landscapes, the representation of "immateriality" as material, the author explores the role of landscape in the studies of emotions and how the landscape-rooted affective elements can be spatially, thus digitally, represented. Furthermore, it reflects on other aspects that go beyond spatial representations - Landscape dynamics, poetics and semantics. It argues for deliberate landscape narratives - stories of survival, power, identity, memory, therefore emotions. The landscape is, thus, meaningful and has its own language. The reading of landscape, entitled "Landscape Literacy", entails both understanding the world and transforming it (Spirn, 2013).

The paper addresses these questions as it traces various examples of mapping approaches to landscape-emotion research. It explores "Emotional Cartographies", firstly, by reviewing how it is practiced and thought about; and, secondly, by testing the application of emotional mapping.

The current research draws on three datasets: first, a corpus of "Emotional Cartographies" - emotional mapping projects in Spain; second, ethnographic data on emotionalscapes in Greece; and, third, The Glossary - The Corpus of Emotional Mapping terms in different languages.

The Emotional Mapping practices are qualitatively analysed through mainly ethnographic study - observation and interviews. Here, the focus is on the mapping as a collaborative and/or participatory process, and knowledge tool. This stage therefore questions the mapping processes, experimental mapping techniques, mapping-out of subjective emotions to the tangible, and the conversion of the qualitative data into a standardized spatial language (if any). This will allow conducting further analysis, such as linguistic semantic analysis of the Glossary of Emotional Mapping. On the other hand, "Emotional Mapping", will be tested as a tool for decoding the stories and narratives on the following: first, ethnobotanical traditional knowledge, embodied in the (Cross)Boarder, former pastoral, landscape of Konitsa (Northern Epirus, Greece); and, second, memory and toponymy of the ancient Minoan, and former pastoral, landscape of Gonies Maleviziou (Crete, Greece). Consequently, broader arguments not only on the challenges of spatially representing "emotions", but also the potential of such cartographies in the re-subjectivization of space, will be provided.

The paper is the part of a doctoral research in progress carried out within the Project "Critical Heritage Studies and the Future of Europe - CHEurope", in the framework of The Marie Skłodowska-Curie Actions (MSCA), Innovative Training Networks (ITN), and within the Doctoral Programme "Interdisciplinary Scientific Strategies in Heritage and Landscape" of the University of the Basque Country (UPV/EHU) in Spain.

\section{Cited References:}

Davidson J, S. M. and B. L. (2007). Emotional geographies. Hampshire, UK: Ashgate Publishing.

Gartner G. (2012). Putting Emotions in Maps - The Wayfinding Example. Wellington: New Zealand Cartographic Society.

Griffin, A. L., \& McQuoid, J. (2012). At the intersection of maps and emotion: The challenge of spatially representing experience. Kartographische Nachrichten.

Nold, C., ed. (2009). Emotional cartography: technologies of the self. Creative Commons.

Pickles, John. (1995). Ground Truth: The Social Implications of Geographic Information Systems. New York: Guilford Press.

D. C. D. Pocock. Transactions of the Institute of British Geographers, Vol. 9, No. 2 (1984), pp. 248-249

Davidson J, S. M. and B. L. (2007). Emotional geographies. Hampshire, UK: Ashgate Publishing.

Griffin, A. L., \& McQuoid, J. (2012). At the intersection of maps and emotion: The challenge of spatially representing experience. Kartographische Nachrichten.

Nold, C. (2009). Emotional cartography : technologies of the self. [publisher not identified].

Spirn, A. W. (2013). The Language of Landscape . Yale University Press. 